\author{
Available online at https://www.rjtl.org \\ Volume: 2, Issue: 2, 88-96, 2021 \\ ISSN: 2708-3632 \\ DOI: https://doi.org/10.46590/rjtl.2021.020204
}

\title{
Development of Needle-Punched Nonwoven Fabrics from Natural Fibers for Sound Absorption Behavior.
}

\author{
K Savitha ${ }^{1}$, Grace S Annapoorani ${ }^{1}$, V R Sampath ${ }^{2 *}$ \\ ${ }^{1}$ Department of Textile and Apparel Design, Bharathiar University, Coimbatore 641 046, India \\ ${ }^{2}$ Ethiopian Institute of Textile and Fashion Technology, Bahir Dar University, Bahir Dar, Ethiopia.
}

\section{Paper History}

Received: March 2021

Accepted: April 2021

Published: May 2021
Corresponding Author

$V R$ Sampath

samsid3@rediffmail.com

\begin{abstract}
The natural fibers prepared from plant waste have parameters like fiber strength, length, and chemical composition which are suitable to fabric and the fibers into nonwoven. The selected plants were identified from their botanical names by comparing the collected samples with those of known identity in the herbarium of a botanical survey in India with their names as Sesbania grandiflora, Mutingia Calabura, and Bauhinia Purpurea. A novel Portable multi-fibre decorticator machine was fabricated and used to extract the fibers from the plant stem and barks. The extracted fibers are done physical characterization and their properties are investigated. The extracted fibers are blended with other natural fibers like jute and flax in appropriate proportions 45:45:10 and nonwoven fabrics were prepared by the needle-punching method. Three and four-layer nonwovens are produced using a needle punching machine. The developed nonwovens are tested using standard apparatus and the effect of natural fibers in areal density, thickness; bulk density, porosity, and air permeability are analyzed. In addition, thermal conductivity and sound absorption behaviour are also investigated. The sound absorption property increases concerning areal density and fabric thickness. The thermal conductivity increased by increasing the fiber layer in the fabric to evaluate its potential as a protective barrier material in non-woven face masks.
\end{abstract}

Keywords: Nonwoven, Needle Punching, Sound Absorption, Thermal Conductivity

Citation: K Savitha, Grace S Annapoorani, V R Sampath", "Development of Needle-Punched Nonwoven Fabrics from Natural Fibers for Sound Absorption Behavior." Research Journal of Textile and Leather, 2(2), 88-96, 2021.

\section{INTRODUCTION}

Technical textiles were developing in many different directions with varying speed and level of success for long years. Technical textiles are becoming one of the most important elements of modern technology and lifestyle and it is present everywhere. Their enduses ranges from simple products such as filters to acoustic and thermal insulation for domestic/industrial applications.

\subsection{Sesbania Grandiflora (NSG)}

Sesbania Grandiflora is a medicinal plant that belongs to the family Leguminosae. The plant contains rich in tannins, flavonoids, coumarins, steroids, and triterpenes. NSG is a thin small erect, fast-growing, and sparsely branched tree that reaches $10 \mathrm{~m}$ in height. The bark of this species is light grey, corky and deeply furrowed and the wood is soft and white. All Sesbania species have compound leaves where each leaf is divided into multiple leaflets which can be up to $30 \mathrm{~cm}$ long with 5-15 paired leaflets that are oblong to elliptic in shape and about $3 \mathrm{~cm}$ in length. The flowers of Sesbania Grandiflora are large (7-9 cm long) shown in Plate Ia.

\subsection{Mutingia Calabura-NMC}

Mutingia Calabura is a fast-growing tree of slender proportions, reaching a height of approximately 7.5$12 \mathrm{~m}$ within early horizontal spreading branches. $\mathrm{NMC}$ is evergreen approximately $5-12.5 \mathrm{~cm}$ long, alternate lanceolate or oblong, long-pointed at the apex, oblique at the base with dark green colour and minutely hairy on the upper surface, grey-or brown hairy on the underside and irregularly toothed The flowers are approximately $1.25-2 \mathrm{~cm}$ wide. The fruits are abundant, in round shape;approximately1$1.25 \mathrm{~cm} w i d e$, with red or yellow, thin, smooth, tender skin and light brown, soft, juicy pulp, with very sweet, musky,fig-like flavour, and filled with exceedingly tiny, yellowish seeds were shown in Plate Ib. 




Plate 1a.

Plate $1 b$.

Plate 1c.

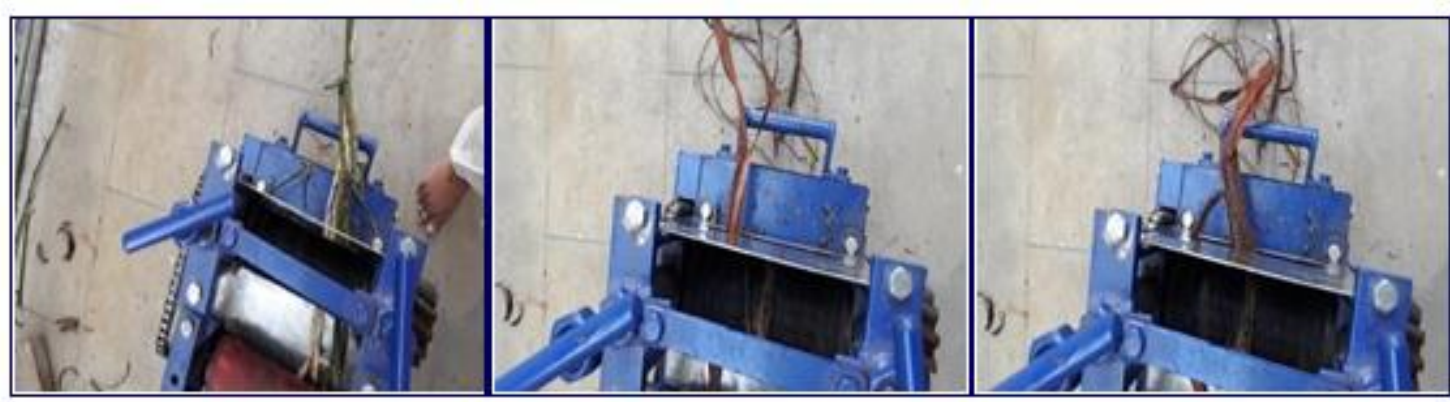

Plate 1d. Decorticator Machine

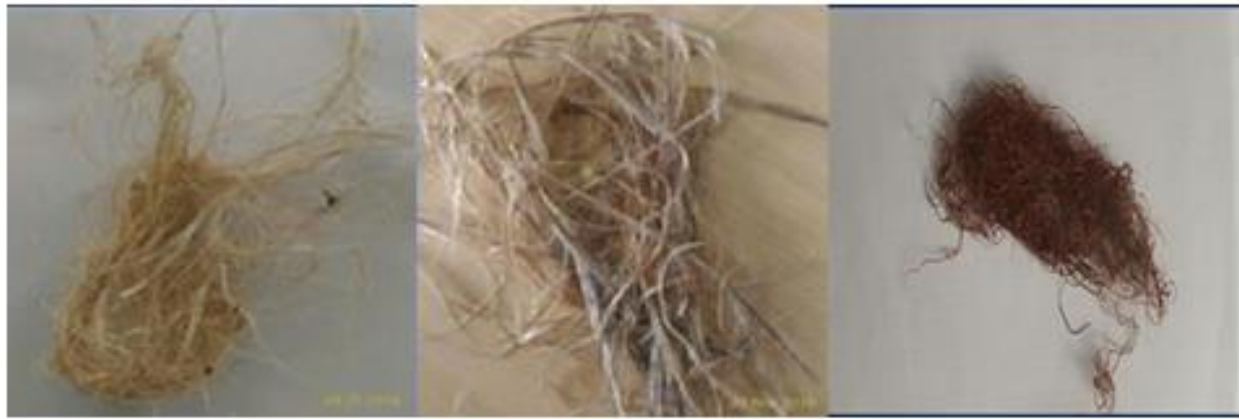

Plate 1e. NSG Fiber

Plat 1f. NMC Fiber

Plate 1g. NBP Fiber

Plate 1. Extraction of fibers from different plants

\subsection{Bauhinia Purpurea-NBP}

Bauhinia Purpureais a flowering plant species belonging to the family Leguminosae, commonly found in Southeast Asia. Different parts of this plant have been used in traditional medicine to cure a host of illness such as body pain, rheumatism, fever, dropsy, stomach tumour, skin diseases, septicemia, and diarrhoea. The leaf, bark, and root of this plant have shown sign of analgesic, anti-inflammatory, antipyretic properties were shown in Plate 1c.

\subsection{Cutting and Blending of Fibers}

Sesbania Grandiflora, Mutingia Calabura, and Bauhinia Purpurea are blended with fibers jute and flax (6) in different percentages which will enhance the performance and improves the aesthetic qualities of the fabric as cited in (www.fabric.link.com/ blends.html). The ratio of the needle-punched nonwoven process is presented in Figure 1.

The arrangement of the fibers and their orientation distribution are related to the mechanical structure of the web Fiber orientation has a big influence on the tensile strength of the nonwoven material.

Uneven distribution in fiber orientation results in anisotropic behaviours in mechanical properties. Plate 2 (a, b, c, and d) shows the photo images of the instruments used for the needle-punching process. 


\section{Development of needle punching Nonwoven}

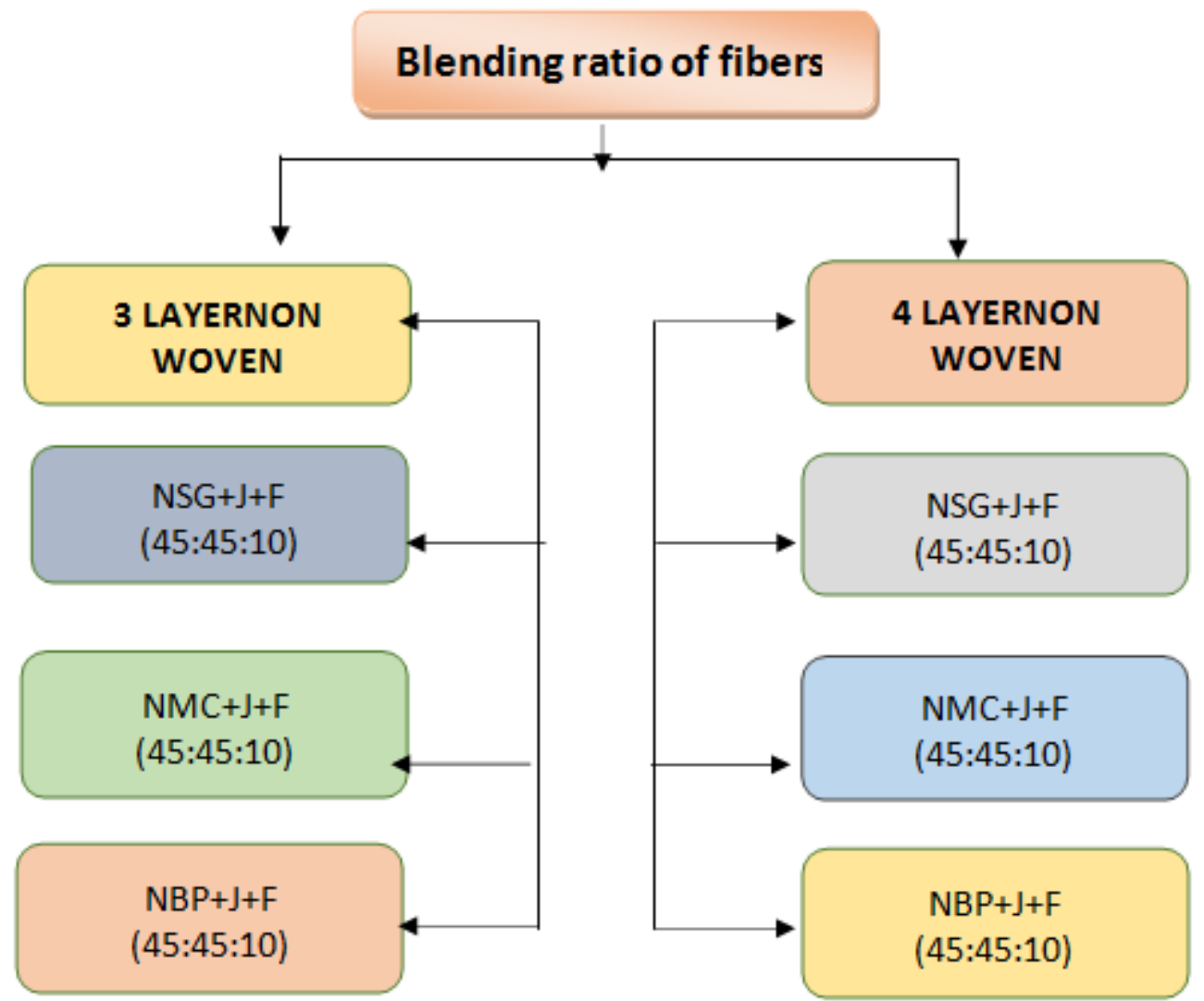

F-Flax; J-jute, NSG- Sesbania Grandiflora; NMC-Mutingia Calabura; NBP- Bauhinia Purpur

Figure 1. The blending ratio of the needle-punched nonwoven process

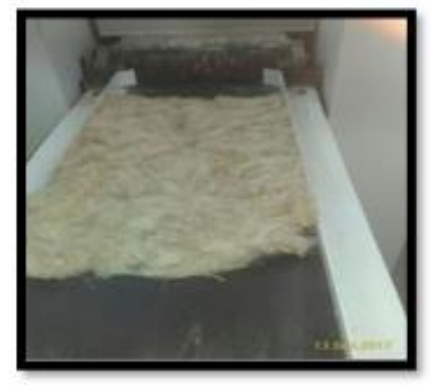

(a) Conveyor Belt

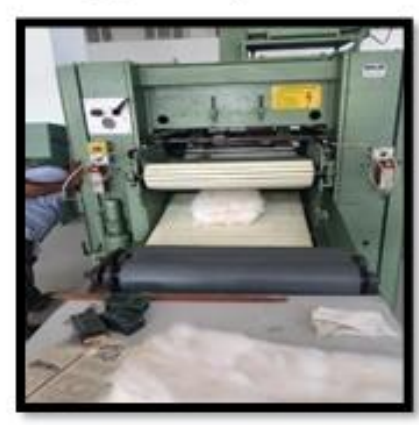

(c) Needle punching

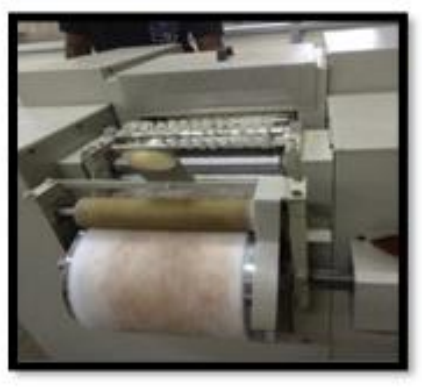

(b) Web layer

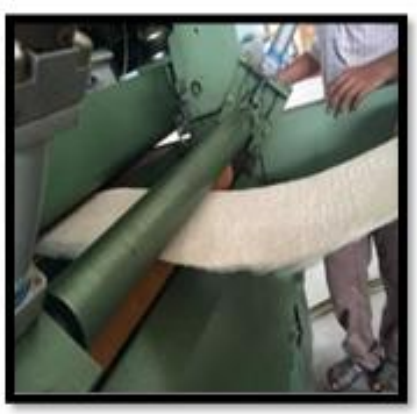

(d) Nonwoven Fabric

Plate 2. Needle-punching process 


\subsection{Fiber Carding}

Carding is a mechanical process that starts with the opening of fibres which are blended and conveyed to the next stage. The tuft is fed into the card teeth. The toothed roller interacts to produce the separation of fiber. The web can be parallel-laid, where most of the fibers are laid in the direction of web travel. Each web was processed through the carding machine and needle-punching (two times) to develop the complete nonwoven

\subsection{Needle-punching process}

After the web formation, the webs were laid one upon another. The laying process was carried out to increase the thickness of the web. Whenever it is required, the thickness can be obtained for the end product. The produced web was needle-punched using DILO needle-punching machine. The web layer was compressed to form flexible nonwoven. Needle punching is the processes of bonding nonwoven web structures by mechanically interlocking the fibers through the web.1200 barbed felting needles are punched vertically through the web to hook and entangled tufts of fibers. Needles punched non-woven resemble felt in appearance barbed needles mounted on a punch fiber into the web and then withdraw leaving the fibers entangled by varying the stroke per minute, the advance rate of the web, and the degree of penetration of the needles, a wide range of fabric densities can be achieved. The nonwoven fabrics were developed at 300 punches/sq.cm speed of 257 cycles/min and at $11 \mathrm{~mm}$ needle penetration depth using a barbed needle.

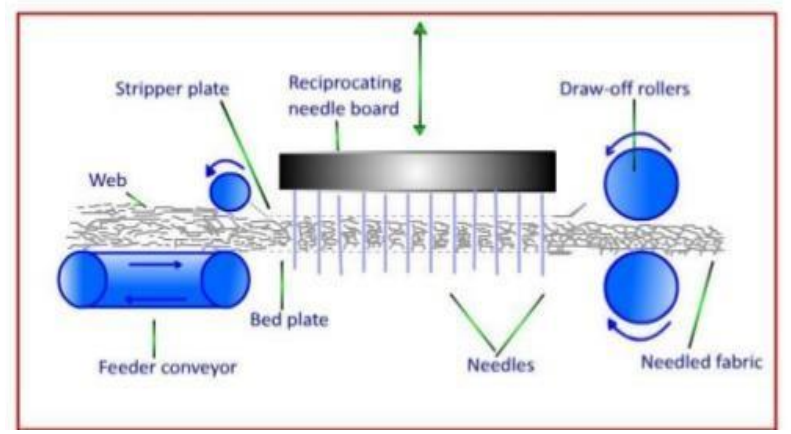

Figure 2. Schematic diagram of the needle-punching process

\section{TESTING METHODS}

\subsection{Sound Absorption Coefficient Measurement}

The sound absorption test was carried out at the Indian Institute of Technology, Chennai, Tamilnadu, India using Standing Wave Apparatus. The acoustic test unit composed of a loudspeaker, amplifier, and impedance tube, microphone probe, oscilloscope, and waveform generator as shown in Figure 3.

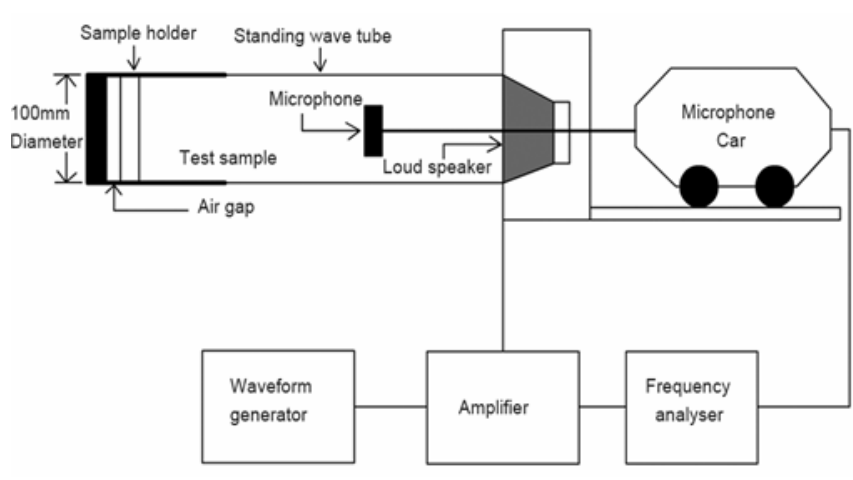

Figure 3. Schematic representation of standing wave apparatus

A loudspeaker produces an acoustic wave that travels down the pipe and reflects from the test sample. The phase interference between the waves in the pipe which are incident upon and reflected from the test sample result in the formation of a standing wave pattern in the pipe. The required frequency is generated using a waveform generator; the microphone attached to the microphone car was moved back and forth to measure the minimum and maximum sound pressure levels. If $100 \%$ of the incident wave is reflected in the incident and reflected waves have the same amplitude; the nodes in the pipe have zero pressure and the antinodes have double the pressure. If some of the incidents sound energy is absorbed by the sample, then the incident and reflected waves have different amplitudes; the nodes in the pipe no longer have zero pressure. The pressure amplitudes at nodes and antinodes are measured with a microphone probe attached to a car that slides along a graduated ruler.

The ratio of the pressure maximum (antinode) to the pressure minimum (node) is called the standing wave ratio (SWR). Plate-IX images of standing wave apparatus. The absorption coefficient was calculated as the average value of three cylindrical foam pieces of dimension $90 \mathrm{~mm}$ in diameter and $15 \mathrm{~mm}$ thick for different frequencies in the range from 100 to $2000 \mathrm{~Hz}$. Sound absorption Coefficient $(\alpha)$ can be defined as the ratio of energy absorbed by a material to the energy incident upon its surface.

Thus SWR = (A + B) / (A - B) (1.7)

Where $A+B$ is pressure maximum, $A-B$ is pressure minimum.

The reflection coefficient $R$ is defined by

$\mathrm{R}=\mathrm{B} / \mathrm{A}=(\mathrm{SWR}+1) /(\mathrm{SWR}-1)(1.8)$,

The sound absorption coefficient,

$\alpha=1-\mathrm{R} 2=1-(\mathrm{SWR}-1) 2 /(\mathrm{SWR}+1) 2$ (1.9)

Absorption coefficient is $\alpha=1$ - R 2 (1.10) 
A loudspeaker produces an acoustic wave that travels down the pipe and reflects from the test sample. The phase interference between the waves in the pipe that are incident upon and reflected from the test sample result in the formation of a standing wave pattern in the pipe.

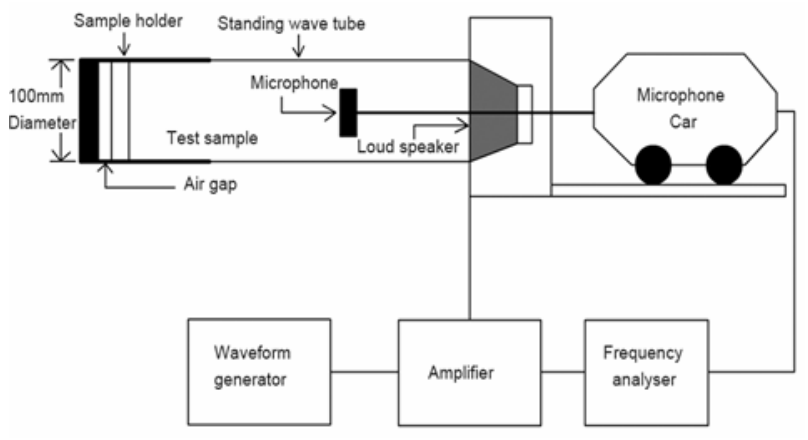

Figure 3. Schematic representation of standing wave apparatus

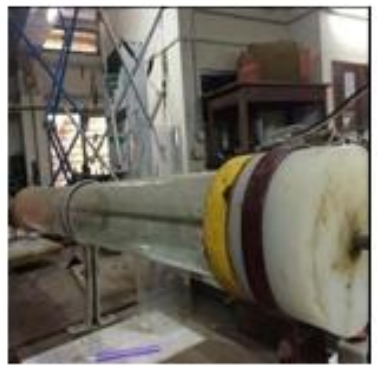

(a) Impedance tube

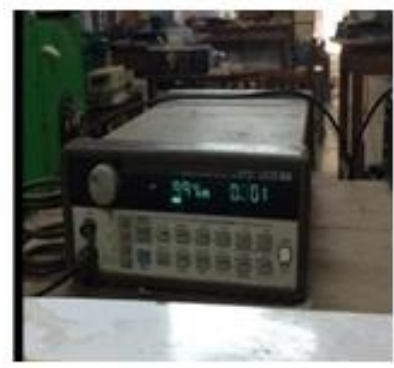

(c) Functional generator



(b) Microphone car



d) Frequency analyzer
Plate 3. Standing wave apparatus

\section{RESULT AND DISCUSSION}

The properties of the needle punched non woven fabric samples were measured and the average value of the samples are tabulated in Table1.

\subsection{Influence of Thickness on Sound Absorption}

Fig. 4 shows the influence of fabric thickness on sound absorption. Out of six blended samples, NSG (4L) displayed the highest thickness of $6.73 \mathrm{~mm}$. Moreover, the blending of natural fibers with these nonwoven fabrics leads to more number of fibers per unit area resulting in an increased thickness of the fabrics. The sound absorption coefficient of the composites was measured and was in the range of $0.4958-0.5464$. The results revealed that the highest sound insulation was observed for the sample NSG (4L). This may be ascribed that when the number of fibers in the fabric increases, the fibers get closer to each other because of the lack of space between each fiber in the fabric. By increasing the fiber mass per unit area, the sound absorption coefficient of the fabric increases.

Figure 5 manifest the graph of areal density against the sound absorption of the fabrics. The areal density increases concerning the number of layers. For each fiber, the four-layered fabric exhibited higher areal density compared to the three-layered fabric. When there is an increase in the areal density there is an increase in sound absorption. The nonwoven fabric NSG (4L) showed the highest areal density of 766 $\mathrm{g} / \mathrm{m} 2$ resulted in the highest sound absorption coefficient of 0.5464 .

The influence of bulk density on the sound absorption coefficient of nonwoven fabrics as shown in Figure 6 revealed that the sound absorption coefficient increases concerning bulk density. The NB (4L) sample showed the highest bulk density of $0.116 \mathrm{~g} / \mathrm{cm} 3$ and exhibited a higher sound absorption coefficient of 0.5022 . This may be due to the density and fineness of the fibers (extracted from the Bauhinia Purpurea plant) is greater than that of other fibers extracted from different plants, which increases the bulk density.

Figure 7 represents the influence of fabric porosity on sound absorption. The fabric porosity of nonwoven fabrics was in the range of $0.633-0.906 \%$. Out of six fabric samples, the NMC (3L) sample exhibited the highest porosity of $0.906 \%$. If the porosity increases, the natural fiber blended nonwoven fabrics allow more air within the structure. The sound absorption decreases as the porosity of the sample increased. The sound absorption coefficient of the NMC (3L) sample was calculated as 0.5022 .

Figure 8 refers to the air permeability of NSG, NMC and NB samples. The deviation among the samples can be tested based upon the fiber type and layer of materials. The air permeability of needle-punched nonwoven samples was in the range of 41.1 - 93.7 $\mathrm{cc} / \mathrm{s} / \mathrm{cm} 2$ with the sound absorption coefficient of $0.4958-0.5464$. The air permeability is inversely proportional to the sound absorption. Moreover, air permeability depends on the porosity of the sample. From Figure 31, it is clear that the NMC (3L) sample showed the lowest air permeability and the highest porosity among the nonwoven samples. However, the sound absorption coefficient of NBP (3L) (0.5016) was lower than that of NSG (4L) sample. 
K Savitha, et.al, Research Journal of Textile and Leather (RJTL), 2(2), 88-96, 2021

Table 1. Physical Properties of Needle-Punched Nonwoven Fabrics

\begin{tabular}{llllllll}
\hline Sample & $\begin{array}{l}\text { Areal } \\
\text { Density } \\
\left(\mathrm{G} / \mathrm{M}^{2}\right)\end{array}$ & Thickness (Mm) & $\begin{array}{l}\text { Bulk } \\
\text { Density } \\
\left(\mathrm{Kg} / \mathrm{M}^{3}\right)\end{array}$ & Porosity $(\%)$ & $\begin{array}{l}\text { Air } \\
\text { Permeability } \\
\left(\mathrm{Cc} / \mathrm{S} / \mathrm{Cm}^{2}\right)\end{array}$ & $\begin{array}{l}\text { Thermal } \\
\text { Conductivity } \\
(\mathrm{W} / \mathrm{Mk})\end{array}$ & $\begin{array}{l}\text { Sound } \\
\text { Absorption } \\
\text { Coefficient }\end{array}$ \\
\hline $\mathrm{NSG}(3 \mathrm{~L})$ & 552 & 6.23 & 0.103 & 0.829 & 93.7 & 0.0565 & 0.5448 \\
$\mathrm{NSG}(4 \mathrm{~L})$ & 766 & 6.73 & 0.113 & 0.817 & 61.2 & 0.0472 & 0.5464 \\
$\mathrm{NMC}(3 \mathrm{~L})$ & 555 & 5.25 & 0.105 & 0.906 & 66.8 & 0.0451 & 0.5022 \\
$\mathrm{NMC}(4 \mathrm{~L})$ & 627 & 5.73 & 0.109 & 0.793 & 41.1 & 0.0353 & 0.5048 \\
$\mathrm{NBP}(3 \mathrm{~L})$ & 544 & 5.22 & 0.104 & 0.762 & 93.4 & 0.0412 & 0.4958 \\
$\mathrm{NBP}(4 \mathrm{~L})$ & 656 & 5.61 & 0.116 & 0.633 & 61.1 & 0.0129 & 0.5016 \\
\hline
\end{tabular}

Table 2. Statistical analysis of Sound Coefficient Natural Fiber Needle Punching Nonwoven Fabrics Using one way ANOVA

\begin{tabular}{|c|c|c|c|c|c|}
\hline Variables (3L and 4L ) & $\begin{array}{l}\text { Source of } \\
\text { square }\end{array}$ & $\begin{array}{l}\text { Sum of } \\
\text { square }\end{array}$ & $\begin{array}{l}\text { Degree of } \\
\text { Freedom }\end{array}$ & $\begin{array}{l}\text { Mean } \\
\text { square }\end{array}$ & Sig. \\
\hline NSG,NMC,NBP & Between & 14.582 & 1 & 14.582 & $\begin{array}{ll}43.718 \quad .000\end{array}$ \\
\hline $\begin{array}{l}\text { Thickness And sound } \\
\text { Absorption }\end{array}$ & $\begin{array}{l}\text { within } \\
\text { Groups }\end{array}$ & 3.336 & 10 & .334 & \\
\hline Total & & 17.918 & 11 & & \\
\hline NSG,NMC,NBP & Between & .002 & 1 & .002 & .259 \\
\hline $\begin{array}{l}\text { Bulk Density and sound } \\
\text { Absorption }\end{array}$ & $\begin{array}{l}\text { within } \\
\text { Groups }\end{array}$ & .067 & 11 & .007 & \\
\hline Total & & .069 & 12 & & \\
\hline NSG,NMC,NBP & Between & 934174.753 & 1 & 934174.753 & 168.601 .003 \\
\hline $\begin{array}{l}\text { Areal Density and sound } \\
\text { Absorption }\end{array}$ & $\begin{array}{l}\text { within } \\
\text { Groups }\end{array}$ & 55407.334 & 10 & 55407.733 & \\
\hline Total & & 989582.088 & 11 & & \\
\hline NSG,NMC,NBP & Between & 2856.658 & 1 & 2856.658 & 139.217 .002 \\
\hline $\begin{array}{l}\text { Air permeability } \\
\text { Density and sound } \\
\text { Absorption }\end{array}$ & $\begin{array}{l}\text { within } \\
\text { Groups }\end{array}$ & 205.194 & 10 & 20.519 & \\
\hline Total & & 3061.852 & 11 & & \\
\hline NSG,NMC,NBP & Between & 15177.847 & 1 & 15177.847 & $93.182 \quad .000$ \\
\hline $\begin{array}{l}\text { Porosity and sound } \\
\text { Absorption }\end{array}$ & $\begin{array}{l}\text { within } \\
\text { Groups }\end{array}$ & 1628.834 & & 1628.834 & \\
\hline Total & & 16806.681 & 11 & & \\
\hline NSG,NMC,NBP & Between & .206 & 1 & .206 & 445.381 .001 \\
\hline $\begin{array}{l}\text { Thermal conductivity } \\
\text { and Sound Absorption }\end{array}$ & $\begin{array}{l}\text { within } \\
\text { Groups }\end{array}$ & .005 & 10 & .000 & \\
\hline Total & & .211 & 11 & & \\
\hline
\end{tabular}




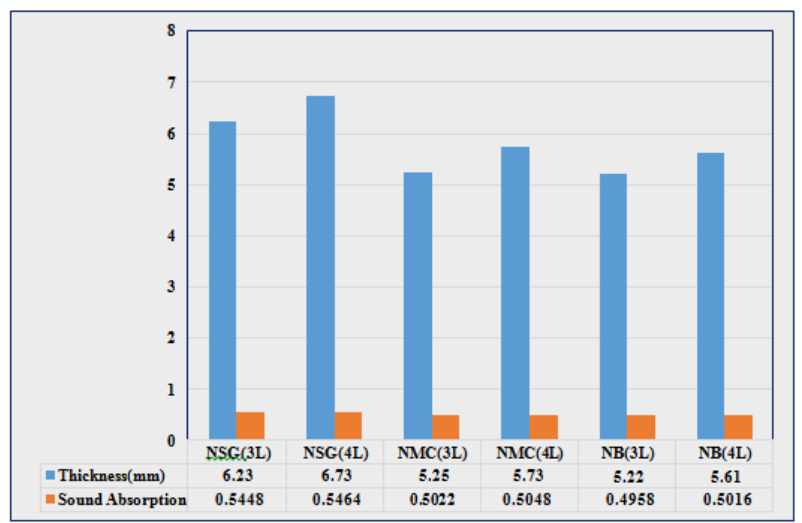

Figure 4. Influence of Thickness on Sound Absorption

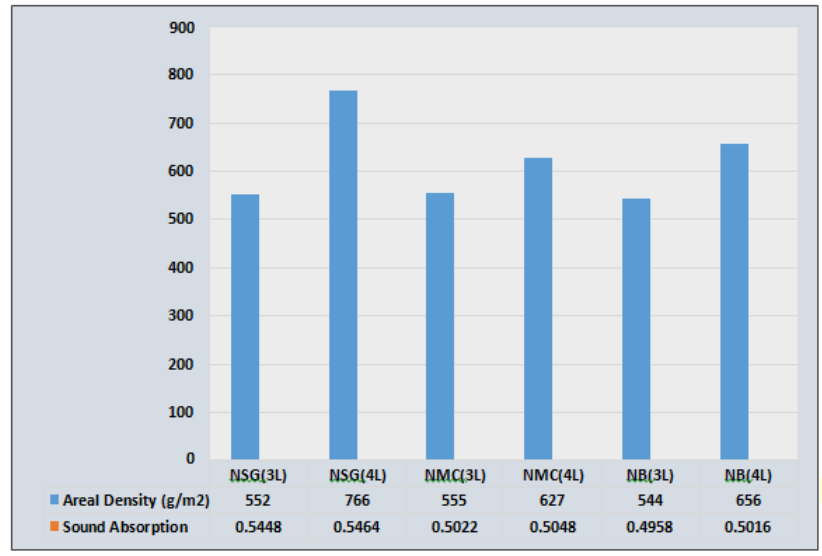

Figure 5. Influence of Areal Density on Sound Absorption

Figure 9 displays the influence of thermal conductivity on sound absorption. It is obvious that the areal density, thickness, and bulk density influence the thermal conductivity. The thermal insulation property varies from $0.0129-0.0565 \mathrm{~W} / \mathrm{mK}$ for fabric samples. The NBP (4L) sample showed the lowest thermal insulation property of $0.0129 \mathrm{~W} / \mathrm{mK}$ because of its higher bulk density. On the other hand, the NSG (4L) sample resulted in the highest thermal conductivity of 0.0565 $\mathrm{W} / \mathrm{mK}$ and a sound absorption coefficient of 0.5448 .

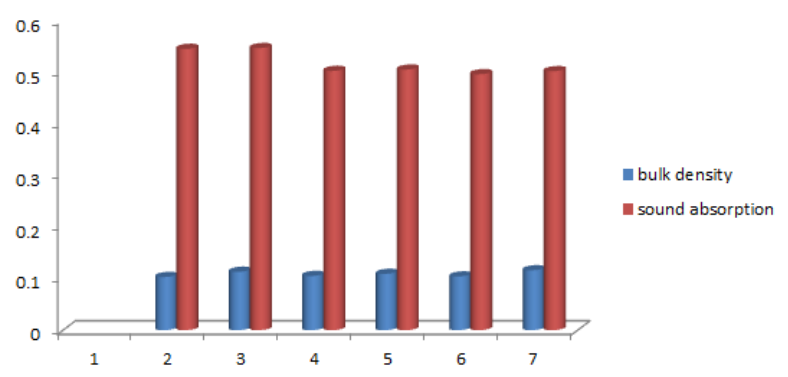

Figure 6. Influence of bulk density on sound absorption

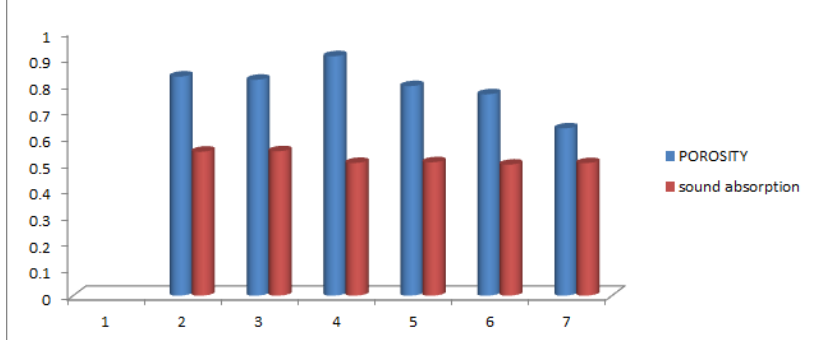

Figure 7. Influence of porosity on sound absorption

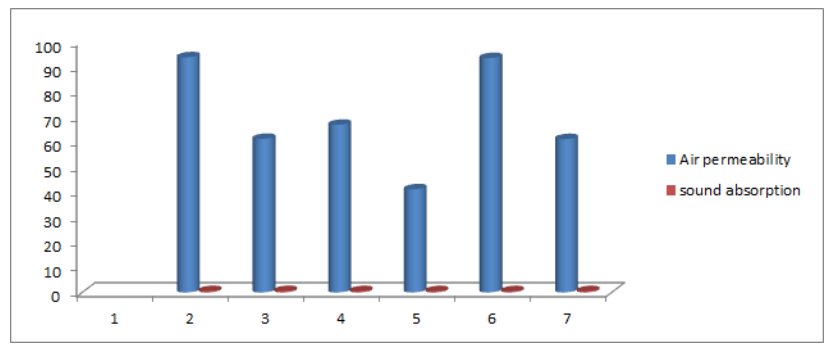

Figure 8. Influence of air permeability on sound absorption



Figure 9. Influence of thermal conductivity on sound absorption



Figure 10. Sound absorption performance of non woven fabrics at different frequencies

Different natural fibers have different properties especially in the consideration of surface and inner stitch bonding properties which influence the density of nonwoven fabrics, which in turn affect the sound absorption of the fabrics. Figure 10 represents the plot of frequency versus sound absorption coefficient of natural fiber stitch-bonded nonwoven fabrics. From Figure 33, it can be observed that while the frequency increases the sound absorption coefficient increased. At the highest frequency of $2000 \mathrm{~Hz}$, the sound absorption coefficient values of NSG (3L), NSG (4L) NMC (3L), 
NMC (4L), NB (3L), NB (4L) samples were 0.5048, $0.4958,0.5022,0.5016,0.54$, and 0.54 , respectively. The small increase in thickness or fiber content of this nonwoven did not influence the sound absorption. The experimental results were statistically calculated by using a one-way ANOVA in SPSS software. The results revealed that there was a significant difference between the sound absorption nonwoven materials.

\section{CONCLUSION}

The automotive and construction interiors made up of recycled fibers are in potential market growth. The recycled fiber nonwoven as acoustic absorption materials was developed by using the fibers from the plant waste of Sesbania Grandiflora, Mutingia Calabura, and Bauhinia Purpurea. The sound absorption property increases concerning areal density and fabric thickness. The thermal conductivity increased by increasing the fiber layer in the fabric. The nonwoven NSG (4L) sample with a thickness of 6.73 $\mathrm{mm}$ showed the highest sound absorption of 0.5464 . It was observed that the NSG (4L) nonwoven sample displayed the highest sound absorption coefficient in the lower and higher frequency levels. This may be ascribed that when the number of fibers in the fabric increases, the fibers get closer to each other because of the lack of space between each fiber in the fabric. By increasing the fiber mass per unit area, the sound absorption coefficient of the fabric increases. The higher porosity in the fabric tends to increase the air permeability which is one of the main parameters for sound absorption.

\section{BIBLIOGRAPHY}

1. Ticoalu, A., Aravinthan, T. and Cardona, F, "A review of current development in natural fiber composites for structural and infrastructure applications", Southern Region Engineering Conference, Toowoomba, Vol. 18 No. 4, pp. 351-363.

2. Fiore, V., Scalici, T. and Valenza, A.(2014) "Characterization of a new natural fiber from Arundo donax $\mathrm{L}$ as potential reinforcement of polymer composites", Carbohydrate Polymers, Vol. 106, pp. 77-83.

3. Al-Kaabi, K., Al-Khanbashi, A. and Hammami, A., "Date palm fibers as polymeric,matrix reinforcement: DPF/polyester composite properties", Polymer Composites, Vol. 26 No. 5, pp. 604-613, (2005).

4. Indran, S. and Raj, R.E, (2015) "Characterization of new natural cellulosic fiber from Cissus quadrangularis stem", Carbohydrate Polymers, Vol. 117, pp. 392-399.

5. Garzón, 1., lópez, 1.m., seminario, j.f., zuluaga, r., betancourt, s., gañan, p. And cruz, 1.j.(2014) A new natural fiber: Toquilla straw a potential reinforcement in thermoplastic polymer composites. In The 5th International Conference On Advanced Materials And Systems (p. 49).

6. Tara Sen, H.N. and Reddy, J.(2011) "Application of sisal, bamboo, coir and jute natural composites in a structural up-gradation", International Journal of Innovation, Management and Technology, Vol. 2, pp. 186-191.

7. R.Nadlene, S.M.SapuaN, M.Jawaid, M.R.Ishak, L.Yusriah ,(2015) Material characterization of roselle fiber (Hibiscus sabdariffa L) as potential reinforcement material for polymer composite, Fib and Tex Eas Eur (6) 23-30 .

8. Venkateshwarlu G, Shantha T.R,Siddhamallayya N Kishor K R, , (2012) Traditional and ayurvedic medicinal importance of agasthya leaves Sesbania Grandiflora W.R.T .ITS Pharmacognostic and Physicochemical evaluation, IJRAP,193-197.

9. Saravanakumar,S, Kumaravel,A.,Nagarajan, T.Sudhakar, P., \& Baskaran, R.. (2013) Characterization of a Novel natural cellulosic fiber from Prosopis juliflora bark. Carbohydrate polymers, 92(2), 1928-1933.

10. Nadlene, R., Sapuan, S. M., Jawaid, M., Ishak, M. R., \& Yusriah, L. (2015), Material characterization of roselle fibre (Hibiscus sabdariffa L.) as potential reinforcement material for polymer composites. Fibres \& Textiles in Eastern Europe.

11. Belouadah, Z., A. Ati, and M. Rokbi. , (2015) "Characterization of new natural cellulosic fiber from Lygeum spartum L." Carbohydrate polymers 134: 429-437.

12. Phologolo, T., Yu, C., Mwasiagi, J. I., Muya, N., \& Li, (2012), Z. F. Production and Characterization of Kenyan Sisal. Asian Journal of Textile, 2(2), 17.

13. Kommula, V. P., Reddy, K. O., Shukla, M., Marwala, T., \& Rajulu, A. (2013) V. Physicochemical, tensile, and thermal characterization of Napier grass (native African) fiber strands. International Journal of Polymer Analysis and Characterization, 18(4), 303-314. 